\title{
Intradural spine surgery may not carry an increased risk of shunt revision compared with extradural spine surgery in pediatric patients with myelomeningocele
}

\author{
Elizabeth N. Kuhn, MD, ${ }^{1}$ Betsy Hopson, MSHA, ${ }^{2}$ Michael J. Conklin, MD, ${ }^{3}$ and \\ Jeffrey P. Blount, MD ${ }^{1,2}$ \\ ${ }^{1}$ Department of Neurosurgery; ${ }^{2}$ Division of Pediatric Neurosurgery, Department of Neurosurgery; and ${ }^{3}$ Division of Orthopedic \\ Surgery, Department of Orthopedic Surgery, University of Alabama at Birmingham, Alabama
}

\begin{abstract}
OBJECTIVE Patients with myelomeningocele are often affected by scoliosis and tethered cord syndrome, and frequently require spine surgery. Intradural spine surgeries may carry an inherently higher risk of inducing shunt malfunction due to entry into the subarachnoid space. In this study, the authors sought to compare rates of shunt malfunction after intradural and extradural spine surgeries among pediatric patients with myelomeningocele.
\end{abstract}

METHODS The authors reviewed records of the National Spina Bifida Program Registry for Children's Hospital of Alabama. The Exago reporting function was used to identify patients who had received at least one of the following procedures: shunt revision, tethered cord release (TCR), or spinal fusion for deformity. The registry records were reviewed for all identified patients to determine if a shunt revision was performed within the 1st year after TCR or spinal fusion.

RESULTS Final analyses included 117 patients, of whom 39 underwent spinal fusion and 78 underwent TCR. Among patients who underwent spinal fusion, shunt revision was performed within 30 days in 2 patients (5.1\%), within 60 days in 2 (5.1\%), within 90 days in $4(10.3 \%)$, and within 1 year in $5(12.8 \%)$. Among patients who underwent TCR, shunt revision was performed within 30 days in 7 patients $(9.0 \%)$, within 60 days in $10(12.8 \%)$, within 90 days in $11(14.1 \%)$, and within 1 year in $17(21.8 \%)$. Using the log-rank test, there was no significant difference in Kaplan-Meier curves between intradural and extradural groups $(p=0.59)$.

CONCLUSIONS In a review of single-institution registry data, the authors found no statistically significant difference in the risk of shunt malfunction after intradural and extradural spine surgeries.

https://thejns.org/doi/abs/10.3171/2017.7.PEDS17274

KEY WORDS myelomeningocele; hydrocephalus; shunt failure; spine surgery

\section{$\mathrm{B}$} ETWEEN $60 \%$ and $95 \%$ of patients with myelomeningocele (MMC) have hydrocephalus, and the majority require shunt placement for CSF diversion. ${ }^{9,17,20}$ Tethered spinal cord is common among patients with MMC, especially those with concomitant scoliosis. ${ }^{2,6}$ Thirty-two percent of patients with MMC will require tethered cord release (TCR) by the time they are young adults. ${ }^{6}$ The TCR procedure is highly effective in reversing or halting the progression of symptoms related to spinal cord tethering, and this benefit persists even for second and multiple repeat TCRs., ${ }^{2,37}$ Scoliosis is present in half of all patients with MMC, and approximately $40 \%$ require spinal fusion. ${ }^{6}$
Anecdotally, it seems that intradural surgery carries an increased risk of shunt malfunction. A relationship between entry into the subarachnoid space, derangement in CSF dynamics, and interruption of shunt function seems biologically plausible and has been reported by several groups. ${ }^{19,23,24}$ Shunt malfunction produces pain, consumes considerable health care resources, and exposes the child to additional shunt-related risks. In this study, we used a cohort study design to compare rates of shunt malfunction after intradural and extradural spine surgeries among pediatric patients with MMC. We hypothesized that there would be a higher rate of shunt revision after intradural compared with extradural spine surgeries.

ABBREVIATIONS EMR = electronic medical record; IQR = interquartile range; MMC = myelomeningocele; NSBPR = National Spina Bifida Program Registry; T/A = tonsillectomy and/or adenoidectomy; TCR = tethered cord release.

SUBMITTED May 21, 2017. ACCEPTED July 13, 2017.

INCLUDE WHEN CITING Published online October 20, 2017; DOI: 10.3171/2017.7.PEDS17274. 


\section{Methods}

All patients with spina bifida, including both open MMC and other closed spinal dysraphisms (for example, spinal lipoma, split cord malformation, and so forth), are regularly followed in our institutional multidisciplinary spina bifida clinic. Patients younger than 21 years are seen at least annually in the Children's Hospital of Alabama Spina Bifida Clinic, whereas those older than 21 years are seen annually in the University of Alabama Adult Spina Bifida Clinic. Patients evaluated in both locations are enrolled in the Centers for Disease Control and Prevention National Spina Bifida Program Registry (NSBPR). Discrete data are entered into the NSBPR electronic medical record (EMR). Certain data elements are de-identified and transmitted to the Centers for Disease Control and Prevention, but all data remain available locally through the spina bifida research EMR. The registry has been approved by our institutional review board. Our clinics enroll more than $99 \%$ of all patients into the NSBPR; therefore, the data in the registry reflect our entire clinic population.

Each patient visit to the pediatric spina bifida clinic includes a meeting with the clinic coordinator. Prior to each clinic visit, the patient's chart is reviewed for previous surgeries done since the last visit. During the clinic visit, this information is reviewed with the family to ensure that all surgical procedures the patient has undergone since the last clinic visit are recorded. In addition, at the time of the first clinic visit, all previous spina bifida-related surgical procedures are recorded. When available, the exact surgery date is recorded and confirmed from the patient's medical record. When the patient and/or family cannot recall the exact timing of surgery, an estimate of the time is recorded and a data field is selected to indicate that the date is a family estimate rather than a confirmed date.

We reviewed the NSBPR EMR as of December 12, 2016. The Exago reporting function was used to identify patients who had received at least one of the following procedures: shunt revision, TCR, spinal fusion for deformity, gastrostomy tube placement, laparoscopic appendectomy, or tonsillectomy and/or adenoidectomy (T/A). The search was filtered based on procedure type, with the following procedures included: correction of scoliosis, creation of ventriculoatrial shunt, freeing of spinal tether, laminectomy with release of tethered lumbar spinal cord, posterior spinal instrumentation, removal of cerebral ventricular shunt, removal of ventriculoatrial shunt, removal of ventriculoperitoneal shunt, removal of ventriculopleural shunt, replacement of ventricular catheter, replacement of ventricular shunt, revision of cerebral ventricular shunt, spinal fusion for kyphosis, spinal fusion for scoliosis, spinal fusion without reduction of spinal deformity, ventriculoperitoneal shunt, ventriculopleural shunt with valve, and ventriculostomy. Patients were excluded if they did not have a shunt in place. Given distortions in anatomy, dural injury during spine surgery can commonly occur. Therefore, for patients who underwent a spinal fusion surgery, operative notes were reviewed in detail to determine if a durotomy occurred. Other data fields collected included name, date of birth, sex, primary diagnosis, race, and ethnicity. The registry records were reviewed for all identified patients to determine if a shunt revision was performed within the 1st year after TCR or spinal fusion. Because we used shunt revision as the outcome, both shunt malfunction and shunt infection were captured. The total number of lifetime revisions prior to nonshunt surgery was also recorded.

A post hoc analysis was performed to include patients from the NSBPR for Children's Hospital of Alabama who had undergone abdominal surgery or T/A. These surgeries were selected because they are performed with relative frequency in the MMC population. They were separated because theoretically, abdominal surgery may influence failure of a ventriculoperitoneal shunt by entry into the peritoneal space, whereas T/A should not influence shunt failure. The Exago reporting function was used to identify patients who had received at least one of the following procedures: shunt revision, TCR, spinal fusion for deformity, gastrostomy tube placement, laparoscopic appendectomy, or T/A. The search was filtered based on procedure type, with the following procedures included: adenoidectomy, laparoscopic appendectomy, laparoscopic insertion of gastrostomy tube, and T/A. The same data fields as above were collected for these groups and the registry records were reviewed to determine if a shunt revision was performed within the 1st year after abdominal surgery or T/A.

A sample size calculation for a cohort study was performed. We used traditional values for confidence level (0.95) and power (0.80). Given an expected incidence of shunt revision of $10 \%$ in the spinal fusion group and an assumed relative risk of 3 , a total sample size of 118 was needed.

Descriptive statistics were applied. Student t-tests and chi-square analysis were used to compare proportions. A Kaplan-Meier curve was constructed depicting freedom from shunt revision. The log-rank test was used to compare Kaplan-Meier curves.

\section{Results}

Our search method produced 122 patients who met the inclusion criteria. Five patients were excluded because they underwent both TCR and spinal fusion on the same day. Of the 117 patients included in the final analysis, 39 (33.3\%) underwent spinal fusion and 78 (66.7\%) underwent TCR. Demographic data on the intradural and extradural groups are shown in Table 1. Patients in the spinal fusion group had an average of 1.3 (SD 2.0) lifetime shunt revisions prior to spine surgery, and patients in the TCR group had an average of 1.5 (SD 2.0) lifetime shunt revisions prior to spine surgery $(\mathrm{p}>0.6)$. The median time since last shunt surgery was 1348 days (interquartile range [IQR] 569-3479) in the spine surgery group and 1434 days (IQR 306-3234) in the TCR group ( $>$ > 0.7).

Among patients who underwent TCR, shunt revision was performed within 30 days in 7 patients $(9.0 \%)$, within 60 days in $10(12.8 \%)$, within 90 days in $11(14.1 \%)$, and within 1 year in $17(21.8 \%)$. Among patients who underwent spinal fusion, shunt revision was performed within 30 days in 2 patients $(5.1 \%)$, within 60 days in $2(5.1 \%)$, within 90 days in $4(10.3 \%)$, and within 1 year in 5 (12.8\%) (Fig. 1). Operative notes for patients who underwent spinal fusion surgery revealed that there was no durotomy in 26 surgeries. A durotomy occurred in 3 surgeries, and operative notes were 
TABLE 1. Comparison of intradural and extradural groups

\begin{tabular}{lccc}
\hline \multicolumn{1}{c}{ Variable } & $\begin{array}{c}\text { Extradural } \\
(\mathrm{n}=39)\end{array}$ & $\begin{array}{c}\text { Intradural } \\
(\mathrm{n}=78)\end{array}$ & $\begin{array}{c}\mathrm{p} \\
\text { Value }\end{array}$ \\
\hline Female sex & $26(67 \%)$ & $39(50 \%)$ & \\
\hline Race & & & \\
\hline White & $37(95 \%)$ & $66(85 \%)$ & \\
\hline Black & $2(5 \%)$ & $8(10 \%)$ & \\
\hline Asian & & $1(1.3 \%)$ & \\
\hline Multiracial & & $2(2.6 \%)$ & \\
\hline Unknown & & $1(1.3 \%)$ & \\
\hline Ethnicity & $38(97 \%)$ & $74(94.9 \%)$ & \\
\hline Not Hispanic/Latino & $1(2.6 \%)$ & $4(5.1 \%)$ & 0.10 \\
\hline Hispanic/Latino & $9.8(3.7)$ & $8.2(4.7)$ & 0.66 \\
\hline $\begin{array}{c}\text { Mean age in yrs (SD) } \\
\text { Mean lifetime prior } \\
\text { shunt revisions (SD) }\end{array}$ & $1.33(2.02)$ & $1.51(2.03)$ & \\
\hline $\begin{array}{c}\text { Median time in days } \\
\text { since last revision } \\
\text { (IQR) }\end{array}$ & $1348(569-3479)$ & $1434(306-3234)$ & 0.74 \\
\hline
\end{tabular}

Values represent the number of patients (\%) unless otherwise indicated.

not available for 10 surgeries. Considering all spinal fusion surgeries as extradural in an "intention-to-treat" analysis, there was no statistically significant difference between groups at any time point ( $>0.2)$. An "as-treated" analysis was also performed in which confirmed extradural surgeries were compared with surgeries that had confirmed dural entry. In this analysis, patients were excluded if there was no operative note available for review. In the "as-treated" analysis, there was no statistically significant difference between groups at any time point $(\mathrm{p}>0.05)$.

Kaplan-Meier curves were constructed showing freedom from shunt revision for the 1st year after spine surgery (Fig. 2). Using the log-rank test, there was no significant difference in Kaplan-Meier curves between "intention-totreat" intradural and extradural groups $(\mathrm{p}=0.59)$.

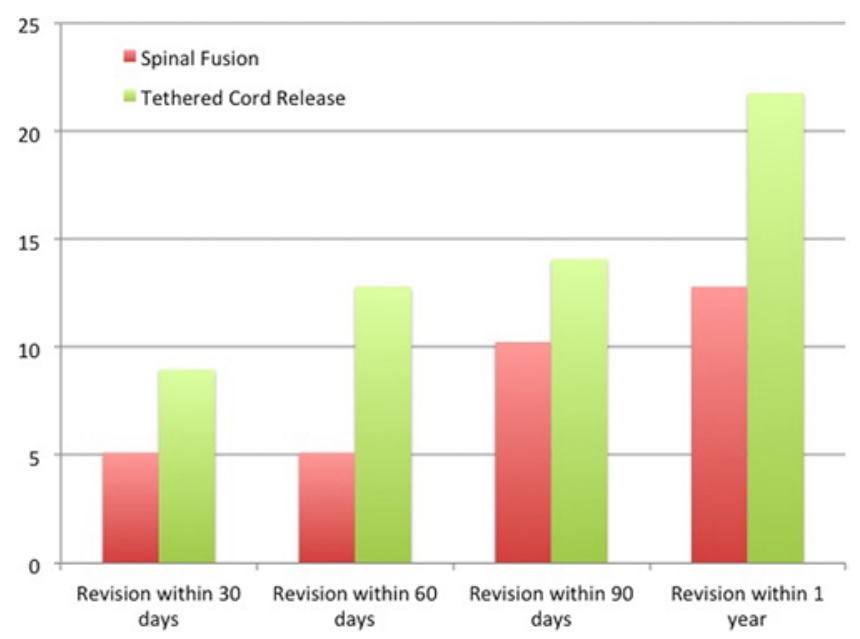

FIG. 1. Bar graph showing comparison of shunt revision rates after spinal fusion and TCR. Values on the $y$-axis denote percentages. Figure is available in color online only.

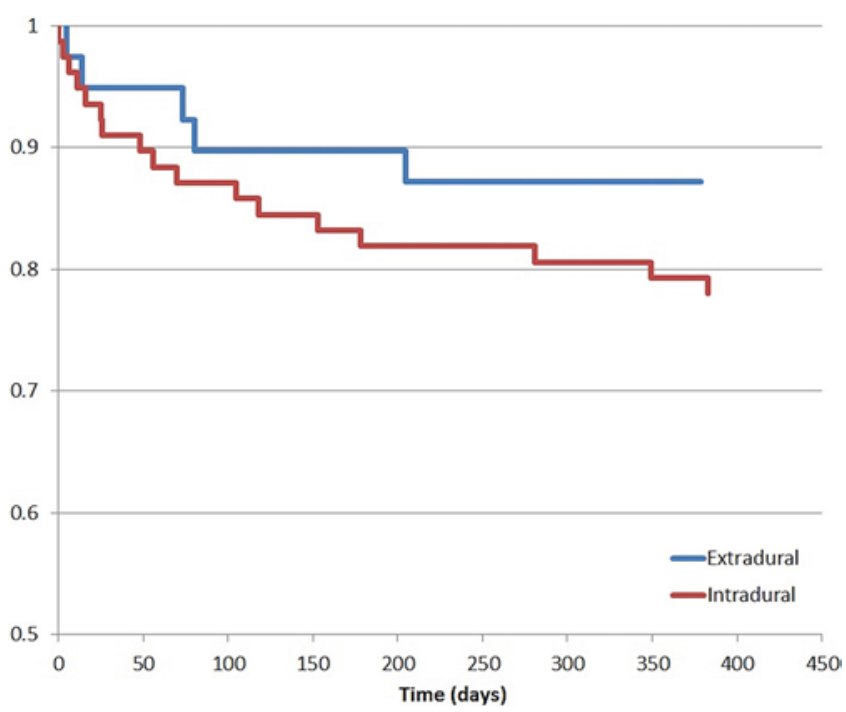

FIG. 2. Kaplan-Meier curve depicting freedom from shunt revision. Figure is available in color online only.

Because there was no significant difference between intradural and extradural spine surgery groups, we performed a post hoc analysis to compare them with 2 additional groups: abdominal surgery and T/A (Table 2). At 30 days, 60 days, 90 days, and 1 year, there was no significant difference between groups according to a chi-square test $(\mathrm{p}>0.2)$. Using a Student $\mathrm{t}$-test to compare the rate of shunt revision between each group at each time point, the following comparisons were statistically significantly different: abdominal surgery versus T/A at 30 days $(\mathrm{p}=$ $0.02)$, abdominal surgery versus spine surgery at 1 year $(\mathrm{p}$ $=0.04)$, and $\mathrm{TCR}$ versus $\mathrm{T} / \mathrm{A}$ at 30 days $(\mathrm{p}=0.03)$.

We hypothesize that if a spine surgery is the cause of shunt failure, the shunt failure should occur shortly after the surgical procedure (i.e., within 30 days). In the 2 patients with spinal fusion who had shunt revision within 30 days, the time to shunt revision was 5 days in one patient and 14 days in the other. In the 7 patients with TCR who had shunt revision within 30 days, the time to shunt revision was $0,3,6,11,16,25$, and 26 days. In the 2 patients who underwent abdominal surgery and who had shunt revision within 30 days, the time to shunt revision was 1 day in one patient and 5 days in the other. Considering all shunt revisions within 30 days of spine surgery, the median time to revision was 6 days (25\%-75\% IQR 3-16).

TABLE 2. Timing of shunt revision after surgery in 117 patients with MMC

\begin{tabular}{lccccc}
\hline & & \multicolumn{4}{c}{ \% Revised, Time Period } \\
\cline { 3 - 6 } Procedure & $\begin{array}{c}\text { No. of } \\
\text { Patients }\end{array}$ & $\begin{array}{c}\text { w/in } 30 \\
\text { Days }\end{array}$ & $\begin{array}{c}\text { w/in 60 } \\
\text { Days }\end{array}$ & $\begin{array}{c}\text { w/in 90 } \\
\text { Days }\end{array}$ & $\begin{array}{c}\text { w/in } \\
1 \mathrm{Yr}\end{array}$ \\
\hline Abdominal & 16 & 12.5 & 12.5 & 12.5 & 37.5 \\
\hline T/A & 38 & 0 & 7.9 & 10.5 & 23.7 \\
\hline Extradural & 39 & 5.1 & 5.1 & 10.3 & 12.8 \\
\hline Intradural & 78 & 9.0 & 12.8 & 14.1 & 21.8 \\
\hline
\end{tabular}




\section{Discussion}

In this study, we compared shunt revision rates after spinal fusion and TCR among patients with shunted hydrocephalus and MMC. At baseline, there was no significant difference between groups with regard to age, average prior shunt revisions, and time since last shunt revision. We found a 30-day shunt revision rate of $5.1 \%$ in the spinal fusion group and $9.0 \%$ in the TCR group. At 30 days, 60 days, 90 days, and 1 year, there was no statistically significant difference in shunt revision rates. Similarly, there was no significant difference between their respective Kaplan-Meier curves. Among patients who experienced shunt failure within 30 days, the median time to shunt revision was 6 days.

Preventable causes of shunt malfunction are under intense study in pediatric neurosurgery. Al-Tamimi et al. report that $12.9 \%$ of all new shunts fail within 30 days of placement, and $28.8 \%$ fail within 1 year. ${ }^{4}$ Subsequent shunts have even higher rates of revision: $20.7 \%$ within 30 days and $40.4 \%$ within 1 year. Similarly, Rossi et al. report a 90-day shunt failure rate of $24.1 \%$ and a 180 -day shunt failure rate of $29.9 \% .^{22}$ Notably, these rates are for shunts placed for any indication, and may not accurately represent the population of MMC patients with shunted hydrocephalus. Overall, the risk for shunt failure in MMC is highest within the 1st year of life, with declining risk thereafter, except for a spike in the early teenage years. ${ }^{11}$ A large registry-based study estimated that the shunt revision rate is 0.23 revisions per patient in the 1 st year of life. ${ }^{11}$ Thereafter, the rate of shunt revision can be estimated using the function $(y=-0.04 \ln ($ age $)+0.17)$.

Shunt-related complications have been recognized as a result of a variety of nonneurosurgical procedures. . $^{5,8,10,15}$, ${ }^{16,18}$ A 5-fold decrease in shunt survival has been reported for shunts placed within 1 year of abdominal surgery. ${ }^{16}$ In another study, there was no association between abdominal surgery and shunt survival if the shunt surgery was performed at least 2 weeks after the abdominal surgery. Within 2 weeks, however, there was a significant association with time to shunt failure, with a hazard ratio of 3.6. ${ }^{8}$

We chose abdominal surgery and T/A as controls for several reasons. First, we wanted to select surgical procedures that were not likely to relate to the patient's diagnosis of MMC. For example, need for appendectomy and/or T/A is probably unrelated to the patient's spina bifida and/or severity of illness. Other surgical procedures, such as tendon release, may be confounded by the level of dysraphism and functional status. In choosing abdominal surgeries and T/A, we hoped to avoid selection bias that may over- or underrepresent certain subgroups of MMC. We chose to dichotomize abdominal surgeries and nonabdominal surgeries because several groups have reported an increased risk of shunt malfunction after intraabdominal surgery, as described above. Although we did not find an increased risk of shunt malfunction after abdominal surgery, our study was not powered to do so.

Shunt failure after intradural surgery was first observed by Tubbs et al. in a series of 5 pediatric patients who had undergone TCR, spinal cord transection, or partial dorsal rhizotomy. ${ }^{23}$ They postulated that these patients had suboptimally functioning shunts preoperatively. After opening of the spinal subarachnoid space and drainage of
CSF, a pressure gradient could have led to ventricular CSF drainage and ventricular catheter obstruction. Their hypothesis was supported by gross findings of choroid plexus ingrowth in ventricular catheters from all 5 patients. Alternatively, a poorly positioned ventricular catheter was postulated to contribute to these shunt failures. ${ }^{21}$ Venable et al. attempted to quantify the risk of shunt malfunction after elective intradural surgery and found a shunt failure rate of $10.7 \%$ within 90 days, with a median of 5 days from intradural surgery to shunt revision. ${ }^{24}$ These rates of shunt revision are comparable to those found in our study. Interestingly, in the study by Venable et al., none of the 17 patients with dysraphism-associated hydrocephalus experienced shunt failure after intradural surgery.

Several groups have published small case series of acute shunt malfunction following posterior spinal fusion for scoliosis. ${ }^{1,12,14}$ It is suggested that spinal fusion for deformity correction can result in fracturing or disconnection of indwelling shunt tubing-especially if calcified-or migration of the distal catheter outside of the peritoneum if there is insufficient redundant length of catheter within the peritoneum..$^{14}$ In the absence of mechanical disruption of the shunt system, deformity correction may conceivably lead to shunt malfunction as a result of perturbations in patterns of CSF flow and reabsorption. ${ }^{25}$

Some have suggested that TCR and spinal fusion can be performed concurrently. Ko et al. report a series of 9 patients with MMC who were treated with combined spinal cord transection and spinal fusion; in this series, $22 \%$ of patients required shunt revision within 6 weeks of surgery. ${ }^{13}$ This figure seems substantially higher than the $5.1 \%-9.0 \%$ rate of shunt revision within 30 days found in our study. Of note, 5 patients were excluded from our analyses because they underwent spinal fusion and TCR in a single surgical procedure. Of those patients, 2 (40\%) required shunt revision within 30 days (13 and 18 days, respectively). Although there is insufficient power for statistical comparisons, there seems to be a trend of higher rates of shunt revision when spinal fusion and TCR are performed together.

There were several patients in the spinal fusion group who in fact had durotomy at the time of surgery. We performed both "intent-to-treat" and "as-treated" analyses; in this case, whether we intended to enter the spinal subarachnoid space and whether we actually entered that space. Neither analysis showed a statistically significant difference between groups. The "intent-to-treat" analysis represents a real-world comparison of the risk of shunt failure after spinal fusion and TCR. The "as-treated" analysis provides a more accurate assessment of the relationship between entrance into the spinal subarachnoid space and shunt failure.

Several limitations of this study are worth noting. The number of patients experiencing shunt failure is low, and our sample size may be insufficiently powered to detect a small difference between groups. As is true in many studies of shunt function, it is challenging to know the preoperative shunt status for patients in the study. It is difficult to ascertain whether a patient's shunt function was already marginal prior to surgery and, similarly, the patient's degree of shunt dependence. The functional status of a shunt is a true challenge in hydrocephalus research. It is a prime 
example of a "Schrödinger's cat" dilemma. The state of a shunt (functional, marginally functional, or nonfunctional) can only be ascertained by surgical exploration ("opening the box"), but exploring and/or manipulating the shunt may itself induce a status change. We used average prior shunt revisions and time since last shunt revision as proxies for preoperative shunt function and/or dependency.

\section{Conclusions}

In a review of single-institution registry data, we found no difference in the risk of shunt malfunction after intradural and extradural spine surgeries. The rates of shunt revision were $5.1 \%-9.0 \%$ within 30 days and $10.3 \%-14.1 \%$ within 90 days. Among patients who experienced shunt failure within 30 days, the median time to shunt revision was 6 days.

\section{Acknowledgments}

Dr. Kuhn completed this work as a University of Alabama at Birmingham Women's Leadership Council Clinical Research Scholar.

\section{References}

1. Abu-Sneineh K, Lipton GE, Gabos PG, Miller F: Dysfunction of a ventriculoperitoneal shunt after posterior spinal fusion in children with cerebral palsy: a report of two cases. J Bone Joint Surg Am 85-A:1119-1124, 2003

2. Al-Holou WN, Garton HJL, Muraszko KM, Maher CO: Secondary tethered cord syndrome in patients with myelomeningocele. J Pediatr Rehabil Med 2:29-36, 2009

3. Al-Holou WN, Muraszko KM, Garton HJ, Buchman SR, Maher CO: The outcome of tethered cord release in secondary and multiple repeat tethered cord syndrome. J Neurosurg Pediatr 4:28-36, 2009

4. Al-Tamimi YZ, Sinha P, Chumas PD, Crimmins D, Drake J, Kestle J, et al: Ventriculoperitoneal shunt 30-day failure rate: a retrospective international cohort study. Neurosurgery 74:29-34, 2014

5. Baird R, Salasidis R: Percutaneous gastrostomy in patients with a ventriculoperitoneal shunt: case series and review. Gastrointest Endosc 59:570-574, 2004

6. Bowman RM, McLone DG, Grant JA, Tomita T, Ito JA: Spina bifida outcome: a 25-year prospective. Pediatr Neurosurg 34:114-120, 2001

7. Bowman RM, Mohan A, Ito J, Seibly JM, McLone DG: Tethered cord release: a long-term study in 114 patients. J Neurosurg Pediatr 3:181-187, 2009

8. Burks JD, Conner AK, Briggs RG, Glenn CA, Bonney PA, Cheema AA, et al: Risk of failure in pediatric ventriculoperitoneal shunts placed after abdominal surgery. J Neurosurg Pediatr 19:571-577, 2017

9. Chakraborty A, Crimmins D, Hayward R, Thompson D: Toward reducing shunt placement rates in patients with myelomeningocele. J Neurosurg Pediatr 1:361-365, 2008

10. Cortés Franco MT, Longás VJ, Cortés Franco S, Cuartero LJ: [Ventriculo-peritoneal shunt valve malfunction in a pregnant woman at full-term.] Rev Esp Anestesiol Reanim 56:259-261, 2009 (Span)

11. Dupepe EB, Hopson B, Johnston JM, Rozzelle CJ, Oakes WJ, Blount JP, et al: Rate of shunt revision as a function of age in patients with shunted hydrocephalus due to myelomeningocele. Neurosurg Focus 41(5):E6, 2016

12. Geiger F, Parsch D, Carstens C: Complications of scoliosis surgery in children with myelomeningocele. Eur Spine J 8:22-26, 1999

13. Ko AL, Song K, Ellenbogen RG, Avellino AM: Retrospec- tive review of multilevel spinal fusion combined with spinal cord transection for treatment of kyphoscoliosis in pediatric myelomeningocele patients. Spine (Phila Pa 1976) 32:24932501, 2007

14. Lai LP, Egnor MR, Carrion WV, Haralabatos SS, Wingate MT: Ventricular peritoneal shunt malfunction after operative correction of scoliosis: report of three cases. Spine J 14: 5e8, 2014

15. Li G, Dutta S: Perioperative management of ventriculoperitoneal shunts during abdominal surgery. Surg Neurol 70:492-497, 2008

16. Li Ching A, Humphrey G, Kamaly-Asl ID: Ventriculoperitoneal shunt survival in children who require additional abdominal surgery-are our estimations of the additional risk accurate? Br J Neurosurg 28:40-48, 2014

17. Liptak GS, Dosa NP: Myelomeningocele. Pediatr Rev 31:443-450, 2010

18. Mortellaro VE, Chen MK, Pincus D, Kays DW, Islam S, Beierle EA: Infectious risk to ventriculo-peritoneal shunts from gastrointestinal surgery in the pediatric population. $\mathbf{J}$ Pediatr Surg 44:1201-1205, 2009

19. Nishiyama K, Mori H, Tanaka R: Changes in cerebrospinal fluid hydrodynamics following endoscopic third ventriculostomy for shunt-dependent noncommunicating hydrocephalus. J Neurosurg 98:1027-1031, 2003

20. Phillips BC, Gelsomino M, Pownall AL, Ocal E, Spencer HJ, O'Brien MS, et al: Predictors of the need for cerebrospinal fluid diversion in patients with myelomeningocele. J Neurosurg Pediatr 14:167-172, 2014

21. Rekate HL: Acute ventriculoperitoneal shunt malfunction following opening of the spinal subarachnoid space. Childs Nerv Syst 25:1395-1397, 2009

22. Rossi NB, Khan NR, Jones TL, Lepard J, McAbee JH, Klimo P Jr: Predicting shunt failure in children: should the global shunt revision rate be a quality measure? J Neurosurg Pediatr 17:249-259, 2016

23. Tubbs RS, Pugh J, Acakpo-Satchivi L, Wellons JC III, Blount JP, Oakes WJ: Acute ventriculoperitoneal shunt malfunction following opening of the spinal subarachnoid space: a case series. Childs Nerv Syst 25:599-605, 2009

24. Venable GT, Green CS, Smalley ZS, Bedford EC, Modica JS, Klimo P Jr: What is the risk of a shunt malfunction after elective intradural surgery? J Neurosurg Pediatr 16:642647,2015

25. Wang Y, Xie J, Zhao Z, Zhang Y, Li T, Si Y: Changes in CSF flow after one-stage posterior vertebral column resection in scoliosis patients with syringomyelia and Chiari malformation type I. J Neurosurg Spine 18:456-464, 2013

\section{Disclosures}

The authors report no conflict of interest concerning the materials or methods used in this study or the findings specified in this paper.

\section{Author Contributions}

Conception and design: all authors. Acquisition of data: Kuhn. Analysis and interpretation of data: Kuhn. Drafting the article: Kuhn. Critically revising the article: all authors. Reviewed submitted version of manuscript: all authors. Approved the final version of the manuscript on behalf of all authors: Kuhn. Statistical analysis: Kuhn. Administrative/technical/material support: Hopson. Study supervision: Conklin, Blount.

\section{Correspondence}

Elizabeth Kuhn, Department of Neurosurgery, University of Alabama, 1720 2nd Ave. South, FOT 1057, Birmingham, AL 35294. email: ekuhn@uabmc.edu. 